\section{Advances in The Management of Organizational Quality: Volume 4}

DB Fedor and S Ghosh (Eds)

JAI Press Inc, 1999. xi +240 pp. \$82.50.

ISBN: 0-7623-0488-X

The editors of this collection declare its mission to be to 'stimulate thinking on quality-related issues and to facilitate bringing quality into the mainstream of organisational effectiveness' (p. ix). I understand the first of these goals, but the precise meaning of the second defeats me; in a way, this is emblematic of the volume as a whole. There is some very interesting material here, and some useful guides to prior work- but there is also much to mystify and some disappointments.

The book opens with an erudite and lengthy piece by Lengnick-Hall which plays with the idea that existing Total Quality (TQ) thinking and practice is premised on stable and repetitive environments and organisations, and, in these 0 so-turbulent times, some new thinking is required. A fter a brief introduction to TQ, there is a lot of discussion on the wild and intriguing world of complex adaptive systems, with allusions to many relevant literatures. This is an important issue, and has much in common with the debates which gently rage in this journal about the prospects for rational intervention in human systems- although the article ignores $B$ eer, Checkland and $M$ ingers and others whose perspectives would be informative. Indeed, Lengnick-Hall's analysis focuses on the dynamic instability of human systems rather than the subtler philosophical problems about system ontology and epistemology. Nevertheless, it would be churlish to complain about such omissions when there is such a fecund supply of citations from strategy, operations and organisational analysis, and even (curiously) the poppsychology of M ichael Scott Peck. The key weakness of the article is that its abstract prognostications are under-illustrated, and careful use of real examples would make the argument more convincing.

Strangely, interesting examples are only a few pages away, and the article by Easton and Jarrell on the Japanese concept of Hoshin Kanri (loosely, 'policy deployment', a neglected element of Japanese TQ thinking which relates to the generation and cascading of plans for operational improvement) would be an excellent starting point for a discussion of Lengnick-Hall's themes. Easton and Jarrell compare the experiences of three US organisations who each work with some variant of the technique, and then contrast these implementations with the 'ideal' Japanese system - a highly formal process of planning and control which seems to lie in diametric opposition to LengnickHall's ruminations on managing complexity. Unfortunately, comparisons are drawn against how Hoshin Kanri is supposed to work in Japan rather than against empirical data from Japanese companies: a matched pair comparison would be more interesting. Nevertheless, the chapter contains some useful commentary and some illuminating insights.

Elsewhere in the book, several papers give rather cursory coverage of important ideas without offering new data or sufficient depth to really push the debates forward: Greller presents an outline of feedback in TQ systems, and Knouse examines reward and recognition schemes. Both will be useful for teaching, but had the two authors collaborated one would have expected a richer set of ideas to emerge. Harvey, Buckley and Novicevic examine the important question of how TQ 'culture' translates across national boundaries in multi-national corporations, but also settle for ruminations and pointers to further work rather than the presentation or discussion of data. Vaughan and Renn present a systematic and informative account of what they term 'C ustomer Service Citizenship B ehaviour', and reflect on how employees and customers interact with the notions of 'organizational justice' and the degree of support perceived to be available in the organisation in regard to customer service. The article is well-argued and thoughtful, and is worth closer reading by anyone interested in the management of services in which direct customer-employee contact is central.

The final chapter, by Handfield, Calantone and Ghosh, is the most disappointing. At last, the reader is offered a chapter with data, but the methods used are suspect and the resulting conclusions are unsupported by the research. Some rather over-ambitious claims do not seem to integrate with the more thoughtful theorisations offered earlier in the book. Incidentally, the authors ignore the controversy regarding the Baldrige award, and the view of WE Deming (whom they cite approvingly) who once wrote that the award 'transgresses all that I try to teach'. ${ }^{1}$

Overall, the volume is a useful addition to the literature, al though it does not live up to its potential. One might hope that for subsequent volumes there might be a greater degree of integration between the contributions, and a more obvious contribution from the academic editors. It is also plagued by more typographic errors, misspelled names, and missing references than one would expect in such an expensively produced book from a respectable publisher.

Saïd Business School, U niversity of Oxford. S New

\section{References}

1 Deming WE (1992). Does the Baldridge award really work? Harvard Bus Rev, January-February: 134.

\section{Doing Critical Management Research}

\section{Alvesson and S Deetz}

Sage, 2000. vii+23 pp. $£ 49.50$ (Cloth) $£ 16.99$ (Paper). ISBN: 0-7619-5332-9 (Cloth) 0-7619-5333-7 (Paper)

This book presents a detailed discussion of the practice of doing critical research on, and in, organisations. The 